\title{
Derecho \& Sociedad
}

"Lo importante no es saber las cosas si no que se den a conocer" (G.G. Márquez)

ISSN 2539-4401
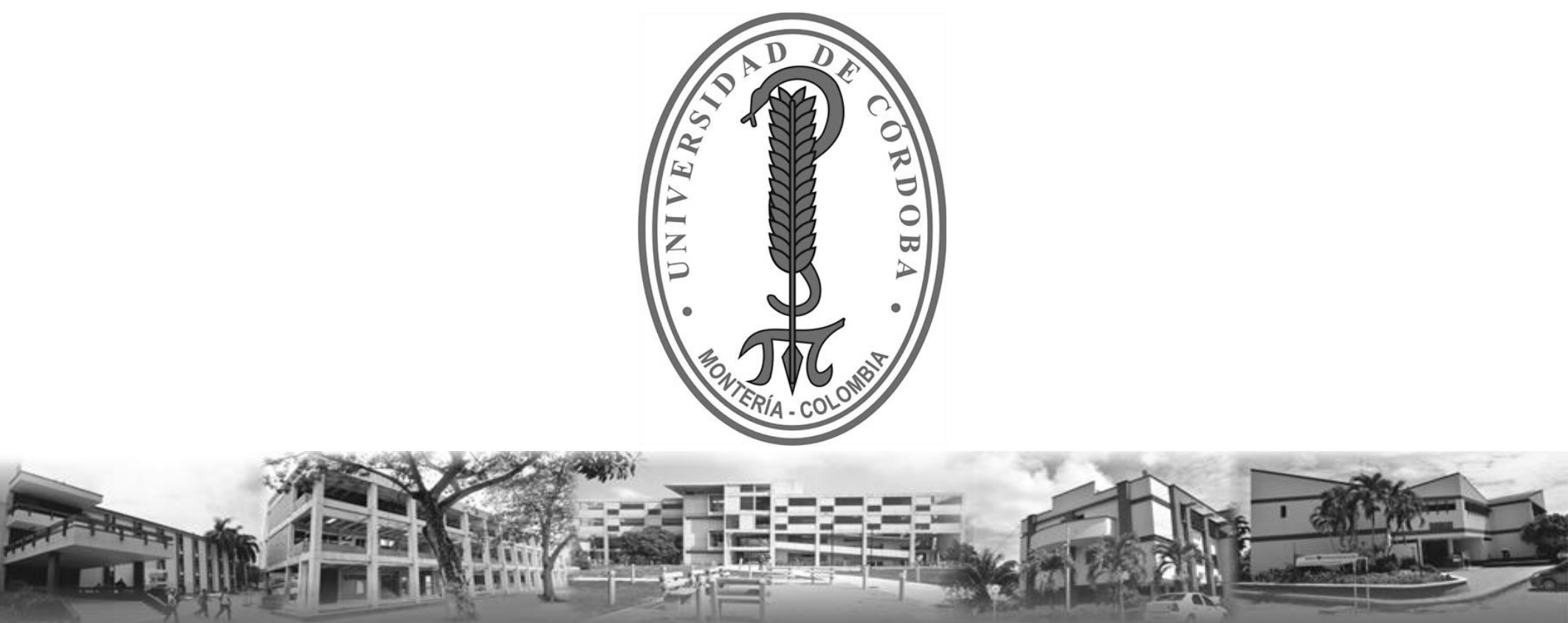

Rumbo a la

ACREDITACIÓN

INSTITUGIONAL

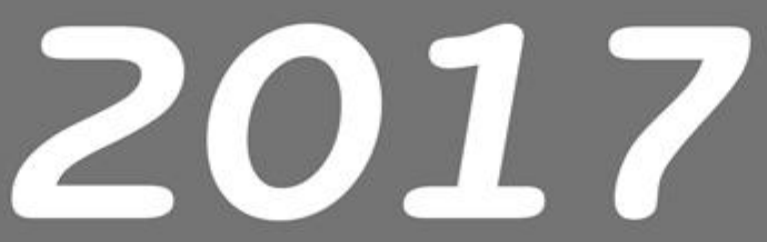


Derecho \& Sociedad es una publicación del Departamento de Ciencias Jurídicas, adscrito a la Facultad de Ciencias Económicas, Jurídicas y Administrativas de la Universidad de Córdoba, su propósito es servir de medio de comunicación para unir a investigadores e intelectuales de habla hispana interesados en los retos y perspectivas de las ciencias jurídicas, especialmente, en el derecho público, desde el que aborda problemas de derecho ambiental y derechos humanos, las ciencias auxiliares y afines.

Esta revista proporciona un acceso abierto inmediato a su contenido, basado en el principio de acceso libre al público a las investigaciones, lo que ayuda a un mayor intercambio global de conocimiento.

Los artículos deberán ser enviados con un resumen no mayor de 950 caracteres sin espacio, con un máximo de seis (6) palabras claves. Las notas de pie de página deben ir numeradas correlativamente. De igual manera los cuadros, tablas y gráficos deben ir numerados y con su correspondiente título y leyenda. Las referencias bibliográficas (fuentes citadas) debe indicarlas dentro del texto con el nombre de autor y, entre paréntesis, el año de publicación. Las referencias bibliográficas se limitaran a las obras citadas en el texto. Se presentarán al pie de página o al final del artículo numerada por orden de aparición. (Autor, año, titulo, ciudad, editorial, paginas) la bibliografía debe citarse al final del artículo, siguiendo el estilo APA, (por sus siglas en inglés, American Psychological Association).

Derecho \& Sociedad / Segundo semestre 2017

ISSN: $2539-4401$

\section{Información}

derechoysociedad@correo.unicordoba.edu.co

http://revistas.unicordoba.edu.co/index.php/dersoc

Editorial Universidad de Córdoba

Cra. 6 No. 76-103, Bloque 19

Montería, Colombia

Teléfono: 7818050

\section{Suscripciones}

derechoysociedad@correo.unicordoba.edu.co

orlandoramon@correo.unicordoba.edu.co

Las opiniones de los artículos solo comprometen a los autores y en ningún caso al Comité Editorial o a la Universidad de Córdoba. Se prohíbe la reproducción total o parcial de los artículos incluidos en esta revista, salvo autorización previa de los autores.

\section{[Editor de la revista]}

\section{ORLANDO RAMÓN ALARCÓN}

\section{Comité editorial}

Dr. Víctor Eligio Espinosa Galán Universidad Pedagógica Nacional

Dr. Oscar Arismendy Martínez

Universidad de Córdoba

Ms. José David Buelvas Bruno

Universidad Cooperativa de Colombia

\section{Comité científico}

Dr. CELIA CRISTINA BASCONZUELO Investigadora adjunta del CONICET Argentina

Dr. FRANCISCO ELVIS RODRIGUES OLIVEIRA Brasil

Dr. Hugo vega vengoA Universidad de Chile

Dr. Mónica ALEJAndRa VARGas aguiRre Universidad de Chile

\section{Diseño edición electrónica}

Ing. Miguel Ángel Vega

\section{Derecho \& Sociedad}

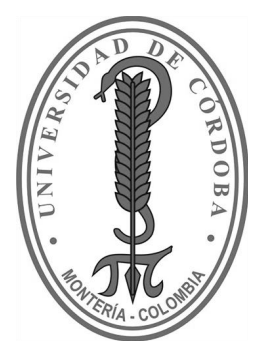

\section{Rumbo a la ACREDITACIÓN INSTITUCIONAL}




\section{Derecho \& Sociedad}

Revista de estudios jurídicos

Número 2 Volumen 1, Segundo semestre 2017

derechoysociedad@correo.unicordoba.edu.co

\section{Contenido}

\section{Editorial}

4

Orlando Ramón Alarcón

Pág. 9

Democracia, internet e intimidad. ¿Civismo anónimo?

Oona Hernández Palma

Pág. 27

Derechos humanos y el derecho a un ambiente sano

Eduardo Arturo Kerguelén Durango

Pág. 41

La experiencia del caso de CEGRA: una propuesta de articulación en redes interuniversitarias e interinstitucionales

Celia Cristina Basconzuelo

Pág. 53

Perspectiva sociológica del contrabando de combustible en la frontera colombo-venezolana

Felipe González Palma

Pág. 70

Interseccionalidad: una mirada hacia grupos poblacionales que ejercen sexualidades subordinadas en Montería

Orlando Ramón Alarcón

Pág. 81

Ciudadanía y construcción democrática

José David Buelvas Bruno 


\section{Editorial}

El Programa de Derecho de la Universidad de Córdoba, constituye un importante soporte científico, humanístico y cultural para el contexto académico de esta institución, por cuanto promueve la libre discusión con perspectiva crítica e investigativa del derecho público, -especialmente-, el derecho ambiental y los derechos humanos y sus ciencias auxiliares y afines.

Esta convicción goza de vital importancia, por la discusión que en los últimos años ha cobrado especial significación, relacionada con los derechos básicos, tipificados en los textos constitucionales y visibilizados en los desarrollos jurisprudenciales, incorporando importantes modificaciones en las diversas áreas del derecho, particularmente, en el derecho público.

Bien conocida es la discusión doctrinal que en las tres primeras décadas del siglo XX en Alemania, sostuvieron Hans Kelsen y Carl Schmitt "sobre la legitimidad de la justicia constitucional. La contundente arremetida de Schmitt puso en entredicho el carácter jurisdiccional del Tribunal Constitucional, y acusó a la institución ideada por Kelsen de socavar el dogma de la división de los poderes públicos, y de hacer de la política un asunto de justicia. Asimismo, el autor alemán presagió que la jurisdicción constitucional llevaría inexorablemente al gobierno de los jueces, y -en las conocidas palabras de Guizot- a la judicialización de la política y la politización de la justicia, con la cual la justicia tenía todo que perder y la política nada que ganar” (Bernal, 2008, p. 30).

En este sentido, las palabras de Louis Joseph Favoreu (2001), adquieren significativa importancia, cuando dice que:

Bajo el efecto del fenómeno de la constitucionalización, el centro de gravedad del orden jurídico se ha desplazado. Desde el siglo XIX, ese orden tuvo a la ley como eje esencial. A partir de fines del siglo XX, el eje es la Carta Fundamental. Hoy debe, en consecuencia, hablarse de principio de constitucionalidad, porque la Constitución no es ya más un Derecho de preámbulo ni otro de índole política, sino que verdadero Derecho (p. 31).

Al margen de ésta discusión, los desarrollos jurisprudenciales han proporcionado variados instrumentos claves para el acceso a la justicia y la defensa de los derechos fundamentales, y también, ha armonizado la crisis estructural de las formas del Estado de derechos, estableciendo límites y prohibiciones; además, de exhortar a los demás poderes del Estado -al menos en Colombia- a que resuelvan de fondo litigios esenciales para determinados intereses y grupos poblacionales. Tales instrumentos no se extinguen en nuestra carta

Derecho \& Sociedad ISSN: 2539-4401 
constitucional, sino que se amplían con el bloque de Convencionalidad que actúa como criterio de garantía de nuestro sistema interno de derechos.

Lo cierto es que estas discusiones, visibilizan una de las cuestiones centrales del derecho contemporáneo: ¿cómo proteger los derechos individuales? O como lo dijera Habermas, ¿cómo garantizar las libertades individuales?, que según este autor alemán generan un nexo con la soberanía popular. En palabras de Barbieri (1989), Habermas habla de un nexo ineludible entre derechos humanos y soberanía popular "puesto que los propios ciudadanos en el proceso de autolegislación evalúan la validez de las normas jurídicas" (p. 5), en ese ejercicio, "la razón comunicativa opera como tejido que articula ese nexo y cuyas células son los actos de habla; y los organoides de dicha célula, el principio discursivo, explicitados en una acción denominada comunicativa, conformando, -de esta manera- el ámbito del discurso práctico" (Alarcón, 2016, p. 45) y teniendo no "más remedio que otorgarse recíprocamente derechos fundamentales de la persona humana" (1989).

Desde este contexto, la revista Derecho \& Sociedad, promueve, a través de sus ediciones, el trabajo investigativo desarrollado por el Grupo de Investigación Derecho \& Sociedad y el Semillero de Investigación Ius-Publicus, del Departamento de Ciencias Jurídicas de la Universidad de Córdoba, en la línea del derecho público. En esta oportunidad, se convocó la presentación de trabajos en el tema de los derechos inherentes a todos los seres humanos.

Por lo tanto, el equipo editorial, decidió animar esta edición invitando al doctor Felipe González Palma, miembro del Grupo de Investigación "Filosofía del Derecho y Derecho Constitucional" clasificado en categoría C por Colciencias y avalado por la Universidad de Cartagena y la Universidad Libre Seccional Cartagena, en esta ocasión trabaja el tema de «Perspectiva sociológica del contrabando de combustible en la frontera colombo - venezolana», esta temática encaja dentro de la discusión de los Principios Rectores sobre la Empresas y los Derechos Humanos; estos Principios se basan en el reconocimiento de: a) Las actuales obligaciones de los Estados de respetar, proteger y cumplir los derechos humanos y las libertades fundamentales; b) El papel de las empresas como órganos especializados de la sociedad que desempeñan funciones especializadas y que deben cumplir todas las leyes aplicables y respetar los derechos humanos; c) La necesidad de que los derechos y obligaciones vayan acompañados de recursos adecuados y efectivos en caso de incumplimiento (Naciones Unidas, 2011). Igualmente, se invitó a la doctora Celia Cristina Basconzuelo, quien tiene una larga y reconocida trayectoria investigativa. 
Celia Cristina Basconzuelo, es doctora en Historia, Licenciada en Historia, Magister en Partidos Políticos, posdoctor del Programa Multidisciplinario de Formación Continua para Doctores en Ciencias Sociales. Al presente, es investigadora adjunta de la Carrera del Investigador Científico y Tecnológico del CONICET en Argentina, docente de la Universidad del Río Cuarto en la Provincia de Córdoba, Argentina, Directora de la Maestría en Ciencias Sociales y Coordinadora del Centro de Estudios y de Gestión en Redes Académicas (CEGRA). Dependiente de la Facultad de Ciencias Humanas de la Universidad del Río Cuarto.

Actualmente, sus mayores esfuerzos intelectuales los dedica trabajando el tema de la experiencia del caso de CEGRA: una propuesta de articulación en redes interuniversitarias e interinstitucionales. Idea que recupera y explicita el compromiso social de la universidad pública y reconoce su antecedente en los postulados básicos de la Reforma Universitaria, episodio emblemático de la Córdoba de los claustros; en el que los jóvenes que impulsaron tal movimiento estudiantil tenían claro que la docencia y la investigación debían estar acompañadas por las actividades de extensión, entendida por entonces como "proyección" hacia el medio (20017).

El ejercicio intelectual de la doctora Basconzuelo, se convierte en una clara y contundente muestra de lucha por el derecho humano a la educación, tal y como lo consagra el artículo 26 de la Declaración Universal de los Derechos Humanos, al estatuir que:

Toda persona tiene derecho a la educación. La educación debe ser gratuita, al menos en lo concerniente a la instrucción elemental y fundamental. La instrucción elemental será obligatoria. La instrucción técnica y profesional habrá de ser generalizada; el acceso a los estudios superiores será igual para todos, en función de los méritos respectivos. La educación tendrá por objeto el pleno desarrollo de la personalidad humana y el fortalecimiento del respeto a los derechos humanos y a las libertades fundamentales; favorecerá la comprensión, la tolerancia y la amistad entre todas las naciones y todos los grupos étnicos o religiosos; y promoverá el desarrollo de las actividades de las Naciones Unidas para el mantenimiento de la paz. Los padres tendrán derecho preferente a escoger el tipo de educación que habrá de darse a sus hijos..." (http://www.pdhre.org/rights/education-sp.html).

Y ratificado por los Estado parte del Pacto Internacional de Derechos Sociales, Económicos y Culturales, como lo indica su artículo 13.

"Los Estados Partes en el presente Pacto reconocen el derecho de toda persona a la educación. ...la educación debe orientarse hacia el pleno desarrollo de la personalidad humana y del sentido de su dignidad, y debe fortalecer el respeto por los derechos humanos y las libertades fundamentales.....la educación debe capacitar a todas las personas para participar efectivamente en una sociedad libre....La enseñanza primaria debe ser obligatoria y asequible a todos gratuitamente....La enseñanza secundaria, en sus diferentes formas, incluso la enseñanza secundaria técnica y profesional, debe ser 
generalizada y hacerse accesible a todos, por cuantos medios sean apropiados, y en particular por la implantación progresiva de la enseñanza gratuita.. La enseñanza superior debe hacerse igualmente accesible a todos, sobre la base de la capacidad de cada uno, por cuantos medios sean apropiados, y en particular por la implantación progresiva de la enseñanza gratuita... Se debe proseguir activamente el desarrollo del sistema escolar en todos los ciclos de la enseñanza, implantar un sistema adecuado de becas, y mejorar continuamente las condiciones materiales del cuerpo docente.... Los Estados Partes en el presente Pacto se comprometen a respetar la libertad de los padres y, en su caso, de los tutores legales, de escoger para sus hijos o pupilos escuelas distintas de las creadas por las autoridades públicas, siempre que aquéllas satisfagan las normas mínimas que el Estado prescriba o apruebe en materia de enseñanza, y de hacer que sus hijos o pupilos reciban la educación religiosa o moral que esté de acuerdo con sus propias convicciones.......Nada de lo dispuesto en este artículo se interpretará como una restricción de la libertad de los particulares y entidades para establecer y dirigir instituciones de enseñanza, a condición de que se respeten los principios enunciados en el párrafo 1 y de que la educación dada en esas instituciones se ajuste a las normas mínimas que prescriba el Estado" (http://www.pdhre.org/rights/education-sp.html).

El trabajo de la doctora Celia Basconzuelo, es propicio para fomentar la reflexión acerca de la situación que atraviesa la Universidad en Colombia, situación tan extrema de negación de principios constitucionales que bien pudiera llevar a la interpretación del poeta Hölderlin de que "allí donde crece el peligro allí está la salvación". El caso es que las universidades, so pretexto de su autonomía desbordan el principio democrático, y lo asumen, sin límites para su ejercicio; negando con ello, el marco jurídico emanado del preámbulo Constitucional, que fortalece la unidad nacional y asegura el disfrute de los valores eminentes; precisamente por estar anclado en solidos soportes. En primer lugar, porque es democrático y reconoce la voluntad popular como base de la existencia y de la actividad del poder público. En segundo lugar, es participativo, porque está orientado por el propósito de hacer efectivo el derecho de todo ciudadano a tomar parte no sólo en la conformación, el ejercicio y control de la autoridad, sino en cualquier decisión que pueda afectarlo.

\section{Orlando Ramón Alarcón} Editor

\section{Referencias}

Alarcón Orlando R. (2016) Aporte iusfilosofico a los alcances del concepto de "tránsito terrestre" a partir del principio discursivo de Jürgen Habermas: Una lectura de la Sentencia C-089/11. Derecho \& Sociedad. Universidad de Córdoba. http://revistas.unicordoba.edu.co/index.php/dersoc/article/view/594/696

Bernal Pulido, Carlos (2008) El derecho de los derechos. Universidad Externado de Colombia. Bogotá 
Barbieri Durão, Aylton (1989) La interpretación de Habermas sobre la tensión entre derechos humanos y soberanía popular en el pensamiento de Kant. Doxa. Cuadernos de filosofía del derecho $\mathrm{N}^{\circ}$ 26. Disponible en: http://publicaciones.ua.es/filespubli/pdf/02148676RD43664827.pdf

Consejo de Derechos Humanos; [ONU] (2011) Principios Rectores sobre las empresas y los derechos humanos: puesta en práctica del marco de las Naciones Unidas para 'proteger, respetar y remediar. Naciones Unidas. Ginebra. Disponible en: http://www.ohchr.org/documents/publications/guidingprinciplesbusinesshr_sp.pdf

Favoreu, Louis Joseph (2001) La constitucionalización del derecho. Revista Derecho (Valdivia). [Online]. Ago. 2001, vol.12, no.1 [citado 10 Agosto 2017], p.31-43. Disponible en la World Wide Web: <http://mingaonline.uach.cl/scielo.php?script=sci_arttext\&pid=S071809502001000100003\&lng=es\&nrm=iso>. ISSN 0718-0950. 